\title{
CASUÍSTICA ODONTOLÓGICA DE ANIMAIS SELVAGENS NO LABORATÓRIO DE ODONTOLOGIA VETERINÁRIA DO HV-UFPR ENTRE MARÇO DE 2019 E FEVEREIRO DE 2020
}

\author{
(Wild animals attended cases in veterinary dentistry laboratory of HV-UFPR between march of 2019 and \\ February of 2020)
}

Dejoara de Angelis Zvoboda, Kimberlly Karoline Correa da Cruz, Helena Baggio Soares, Marcos Vinícius Morais, Thaiza Regina de Lima, Mariana Reffatti de Oliveira, Rogério Ribas Lange

Universidade Federal do Paraná, Curitiba, Paraná, Brasil

*Correspondência: dejoaraz@gmail.com

RESUMO: O Hospital Veterinário da Universidade Federal do Paraná (HV-UFPR) é uma unidade de apoio ao atendimento de animais selvagens de vida livre resgatados e de cativeiro. O Hospital assessora órgãos públicos que realizam resgate de animais de vida livre, como o Instituto Água e Terra, e o Zoológico de Curitiba, prestando atendimento veterinário. Esse recurso é importante em vista necessidade de pronto atendimento sem que estas instituições disponham de estrutura hospitalar. O objetivo desse trabalho é de relatar os casos atendidos no período de março de 2019 a fevereiro de 2020 no Laboratório de Odontologia Veterinária do HV-UFPR. Foram atendidos nove animais selvagens, sendo cinco originários de resgate pelo Instituto Água e Terra e quatro do Zoológico de Curitiba. Dentre as espécies atendidas estão quatro primatas, sendo um deles do velho mundo, dois felídeos, dois didelphídeos e um ursídeo. Dentre os animais resgatados, todos apresentaram fraturas dentárias e/ou ósseas e dentre os animais de cativeiro, um apresentava fratura óssea, um apresentava fratura dentária e um caso de doença periodontal grave necessitando de múltiplas extrações. Em todos os animais foi realizada radiografia intraoral digital e avaliação minuciosa da cavidade oral e dos elementos dentários. Foi realizado o procedimento indicado para cada caso. O condicionamento animal para avaliação oral é muito importante em parques zoológicos para prevenção de afecções orais, pois muitas vezes a doença só é notada quando há sinais graves com comprometimento sistêmico. Nos casos de contenção química de animais selvagens, é fundamental realizar todos os exames possíveis, incluindo o exame completo da cavidade oral.

Palavras-chave: avaliação oral; cativeiro; condicionamento; zoológico 